

\title{
MODIFIKASI PEMANASAN DENGAN MOTIVASI BELAJAR SISWA DALAM PEMBELAJARAN PENDIDIKAN JASMANI
}

\author{
Muhammad Fajri Yusup', Muhammad Mury Syafei ${ }^{2}$, Fahrudin ${ }^{3}$ \\ IProgram Studi Pendidikan Jasmani, Kesehatan dan Rekreasi, Fakultas Keguruan dan IImu \\ Pendidikan, Universitas \\ Singaperbangsa. Jalan H.S. Ronggowaluyo Telukjambe Timur, Karawang, Jawa Barat, 41361, \\ Indonesia \\ Email : mfajriysp@gmail.com', Murysyafei@gmail.com², arrufahrudin@gmail.com³
}

\begin{abstract}
Abstrak
Penelitian ini bertujuan untuk mengetahui hubungan modifikasi pemanasan dengan motivasi belajar siswa dalam pembelajaran pendidikan jasmani pada siswa kelas XI SMA Negeri 1 Jatibarang. Penelitian ini termasuk kategori penelitian kuantitatif dengan metode korelasional. Populasi penelitian ini adalah seluruh siswa kelas XI SMAN 1

Jatibarang yang berjumlah 117 orang dan berjumlah lima kelas yang masing-masing kelasnya berjumlah 23-24 orang. Teknik sampling yang digunakan adalah probability sampling dengan cara simple random sampling, maka

dari itu peneliti mengambiil sampel $50 \%$ dari populasi atau sejumlah 59 siswa agar mewakili keseluruhan populasi tersebut. Pengambilan data dilakukan dengan cara menyebar angket. Analisis statistik yang digunakan adalah uji korelasi, uji determinan, serta uji t. Hasil pengujian korelasi sebesar 0,739 termasuk dalam tingkat hubungan yang kuat. Berdasarkan hasil pengujian determinan diperoleh koefisien determinan sebesar $54,61 \%$ yang artinya modifikasi pemanasan menjadi faktor penting dalam hubungannya dengan motivasi belajar dan sisanya $45,39 \%$ berhubungan dengan faktor lain. Sedangkan hasil uji t diperoleh thitung 8,139 lebih besar dari ttabel 2,002. Dalam hal ini thitung berada pada daerah penolakan $\mathrm{HO}$, jadi $\mathrm{HO}$ ditolak dan $\mathrm{H} 1$ diterima artinya terdapat hubungan yang

signifikan antara modifikasi pemanasan dengan motivasi belajar siswa dalam pembelajaran pendidikan jasmani.
\end{abstract}

Kata Kunci: Modifikasi Pemanasan, Motivasi Belajar Siswa, Pendidikan Jasmani

\section{WARMING MODIFICATION WITH STUDENTS 'LEARNING MOTIVATION IN LEARNING PHYSICAL EDUCATION}

\begin{abstract}
This study aims to determine the relationship between heating modification and student motivation in learning physical education in class XI SMA Negeri 1 Jatibarang. This research belongs to the category of quantitative research with a correlational method. The population of this study were all students of class XI SMAN 1 Jatibarang, amounting to 117 people and totaled five classes, each class numbering 23-24 people. The sampling technique used is probability sampling by means of simple random sampling, therefore the researcher takes a sample of $50 \%$ of the population or a number of 59 students to represent the entire population. Data were collected by distributing questionnaires. The statistical analysis used was the correlation test, determinant test, and $t$ test. The correlation test results of 0.739 are included in the strong relationship level. Based on the results of the determinant test, it was obtained a determinant coefficient of $54.61 \%$, which means that heating modification is an important factor in relation to learning motivation and the remaining $45.39 \%$ is related to other factors. While the $t$ test results obtained tcount
\end{abstract}


8,139 greater than ttable 2,002. In this case tcount is in the rejection area $\mathrm{HO}$, so $\mathrm{HO}$ is rejected and $\mathrm{H} 1$ is accepted, meaning that there is a significant relationship between heating modification and student learning motivation in learning physical education

Keywords: Warming Modification, Student Motivation, Physical Education

\section{PENDAHULUAN}

Pendidikan merupakan kebutuhan yang tidak kalah penting dengan kebutuhan yang lain. Pendidikan bagi manusia sebagai wadah untuk mengembangkan diri agar tidak mudah dibodohi perkembangan dunia. Sekolah merupakan lembaga yang mengindahkan nilai-nilai kebudayaan manusia baik dimasa lalu, masa kini bahkan masa yang akan datang.

Pendidikan jasmani berkewajiban meningkatkan jiwa dan raga yang mempengaruhi semua aspek kehidupan

sehari-hari seseorang atau keseluruhan pribadi seseorang. Pendidikan jasmani menggunakan pendekatan keseluruhan yang mencakup semua aspek baik afektif, kognitif, maupun psikomotor. Pendidikan jasmani merupakan mata pelajaran yang sangat diminati oleh siswa. Namun fakta dilapangan masih banyak siswa yang motivasi belajarnya kurang saat pelajaran pendidikan jasmani olahraga dan kesehatan di sekolah.

Permasalahan yang dihadapi pada umumnya kurangnya inovasi sehingga proses pembelajaran belum semua antusias untuk beraktivitas jasmani. Selain itu permasalahan sering muncul kurangnya pemahaman siswa tentang pentingnya pemanasan sebelum aktivitas gerak, padahal jika siswa bersungguh-sungguh dalam mengikuti pemanasan maka siswa akan dapat melakukan keterampilan secara maksimal dalam proses pembelajaran.

Salah satu cara untuk meningkatkan motivasi belajar siswa yaitu dengan cara memodifikasi pemanasannya. Modifikasi secara umum adalah mengubah atau menyesuaikan. Modifikasi adalah cara merubah sesuatu dari yang kurang menarik menjadi lebih menarik tanpa menghilangkan fungsi aslinya, serta menampilkan bentuk yang lebih bagus dari aslinya.

Seperti yang dikemukakan Bahagia (2010) bahwa "Modifikasi dapat diartikan sebagai upaya melakukan perubahan dengan penyesuaian baik dalam segi fisik material (fasilitas dan perlengkapan) maupun dalam tujuan dan cara (metode, gaya, pendekatan, aturan serta penilaian)". Dari penjelasan tersebut dapat disimpulkan bahwa modifikasi merupakan perubahan yang dilakukan dengan menyesuaikan kebutuhan dan keadaan baik dalam segi fasilitas dan perlengkapan maupun tujuan dan cara. Hal ini dilakukan untuk mengatasi kebosanan atau kejenuhan dalam menjalani kegiatan rutin yang sama berulang-ulang.

Pada dasarnya semua siswa tidak menghendaki adanya kebosanan dalam hidupnya, karena pembelajaran yang membosankan adalah sesuatu yang tidak menyenangkan. Hal ini disebabkan dengan proses belajar mengajar yang tidak diawali dengan sesuatu yang menarik motivasi siswa terhadap pembelajaran pendidikan jasmani, dan akibatnya tujuan pembelajaran tidak tercapai. Untuk mencapai tujuan pembelajaran diharapkan guru mengawali proses pembelajaran dengan pemanasan yang dibuat semenarik mungkin seperti pemberian permainan dalam pemanasan, dan nantinya akan membuat siswa lebih meningkatkan motivasi dalam mengikuti pembelajaran.

Sebagaimana dikemukakan Harsono (2015) bahwa "Sesuai dengan karakter siswa, kebanyakan dari mereka cenderung suka bermain. Karakteristik bermain sebagai aktivitas yang dilakukan secara bebas dan sukarela karena dorongan naluri yang berguna untuk merangsang perkembangan fisik dan mental". Dari pernyataan tersebut dapat disimpulkan guru harus mampu mengembangkan pembelajaran yang efektif, disamping harus memahami dan memperhatikan karakteristik dan kebutuhan siswa.

Banyak orang seringkali mengabaikan proses pemanasan sebelum olahraga. Padahal, pemanasan sangatlah penting dan dibutuhkan sebagai persiapan tubuh sebelum olahraga. Jika pemanasan tidak benar, risiko mengalami cidera akan semakin tinggi. Pemanasan sebelum olahraga sama pentingnya dengan olahraga itu sendiri. Jika tubuh anda tidak siap, otot dan sendi 
tubuh terasa kaku, kram otot dan rasa pegal, maka olahraga tersebut justru akan membahayakan fisik.

Modifikasi merupakan upaya merubah sesuatu menjadi lebih menarik tanpa menghilangkan fungsi aslinya. Menurut Supandi (Muhammad Faizal dan Setyo Hartoto, 2015) mengemukakan bahwa "Modifikasi ialah pengurangan atau pergantian unsur-unsur tertentu." Selain pendapat tersebut menurut Yoyo Bahagia dan Adang.

Suherman (2010) menjelaskan bahwa "Modifikasi merupakan salah satu upaya yang dilakukan oleh para guru agar proses pembelajaran dapat mencerminkan DAP (Developentally Appropriate Practice). Artinya tugas ajar yang diberikan harus memperhatikan perubahan kemampuan anak dan dapat membantu mendorong perubahan tersebut". Adang Suherman (2010) menjelaskan bahwa: "Inti dari modifikasi adalah menganalisa sekaligus mengembangkan materi mata pelajaran dalam bentuk aktivitas belajar potensial yang dapat memperlancar siswa dalam belajarnya".

Sadoso Sumosardjuno (Turas Rio Anggoro, 2016) bahwa "Pemanasan merupakan berbagai macam aktivitas fisik yang mempersiapkan anda untuk menerima beban latihan yang lebih besar intensitasnya". Jadi dalam pemanasan dilakukan aktivitas fisik mulai dari yang intensitasnya rendah kemudian sedikit demi sedikit ditingkatkan.

Yoyo dan Adang (2010) bahwa "Modifikasi pemanasan adalah suatu tindakan hasil perubahan dari program latihan permulaan yang terdiri dari sekelompok latihan gerakan yang dilakukan pada saat hendak melakukan aktivitas olahraga". Selain itu menurut Gusril (2014) menjelaskan bahwa "Modifikasi olahraga dalam pendidikan jasmani sangat diperlukan bagi anakanak, pada dasarnya setiap pembelajaran yang dimodifikasi dengan menggunakan pemanasan bermain dalam bentuk variasi baru akan memberikan peran penting untuk memberi kesan kepada anak pada inti pembelajaran".

Sedangkan Mutohir (2011) menyatakan bahwa "Modifikasi olahraga mendorong anak untuk melakukan tugas gerak dengan tingkat keberhasilan yang lebih tinggi ketimbang pendekatan tradisional. Jika anak sudah mau banyak bergerak maka tingkat kebugaran yang akan didapat maksimal".

Motivasi berasal dari kata motif yang berarti dorongan yang terarah kepada pemenuhan psikis dan rohani. Menurut Oemar Hamalik (2011) menjelaskan bahwa "Motivasi adalah perubahan energi dalam diri (pribadi) seseorang yang ditandai dengan timbulnya perasaan dan reaksi untuk mencapai tujuan".

Sedangkan menurut Sardiman A.M (2010) mengemukakan bahwa "Dalam kegiatan belajar motivasi dapat dikatakan sebagai keseluruhan daya penggerak di dalam diri siswa yang menimbulkan kegiatan belajar, sehingga tujuan yang dikehendaki oleh subjek belajar itu dapat tercapai". Hamzah B. Uno (2011) menjelaskan bahwa "Hakikat motivasi belajar adalah dorongan internal dan eksternal pada siswa-siswa yang sedang belajar untuk mengadakan perubahan tingkah laku, pada umumnya dengan beberapa indikator atau unsur yang mendukung".

Hamzah B. Uno (2011) menyebutkan indikator motivasi belajar, dapat diklasifikasikan sebagai berikut 1) Adanya hasrat dan keinginan berhasil. 2) Adanya dorongan dan kebutuhan dalam belajar. 3) Adanya harapan atau cita-cita masa depan. 4) Adanya penghargaan dalam belajar. 5) Adanya kegiatan yang menarik dalam belajar. 6) Adanya lingkungan belajar yang kondusif, sehingga memungkinkan seorang siswa dapat belajar dengan baik.

Jadi untuk meraih motivasi belajar yang tinggi bagi siswa, harus diperhatikan faktor yang mempengaruhinya baik intrinsik maupun ekstrinsik. Siswa harus menyadari dengan sengaja untuk melakukan kegiatan dan kebutuhan belajar untuk meraih tujuan yang hendak dicapai. Faktor ekstrinsik harus disertai penghargaan atau pujian jika siswa berprestasi, diperlukan lingkungan belajar yang kondusif dan kegiatan belajar yang menarik. Dalam hal ini peran orangtua diperlukan untuk menciptakan suasana yang kondusif dan membantu anaknya dalam belajar.

Rochman Natawijaya (Eva Fauziah, 2013) mengemukakan bahwa "Motivasi adalah suatu proses untuk menggiatkan motif-motif menjadi perbuatan atau tingkah laku, yang mengatur tingkah laku atau perbuatan untuk memuaskan kebutuhan atau menjadi tujuan". 
Menurut Aldermen (Husdarta, 2010) mengatakan bahwa tidak ada prestasi tanpa motivasi. Selain itu juga Husdarta (2010) menjelaskan bahwa "Motivasi adalah energi psikologis yang bersifat abstrak. Wujudnya hanya diamati dalam bentuk manifestasi tingkah laku yang ditampilkan. Motivasi sebagai proses psikologis adalah refleksi kekuatan interaksi antara kognisi, pengalaman dan kebutuhan".

Menurut Kristiandaru (2010) menerangkan bahwa "Pendidikan jasmani adalah bagian dari pendidikan keseluruhan yang mengutamakan aktifitas jasmani dan pembinaan hidup sehat untuk pertumbuhan dan perkembangan jasmani, mental, sosial dan emosional yang serasi, selaras dan seimbang".

Hartono, dkk (2013) menjelaskan bahwa "Pendidikan jasmani pada hakikatnya adalah proses Pendidikan yang memanfaatkan aktifitas fisik untuk menghasilkan perubahan holistik dalam kualitas individu, baik dalam hal fisik, mental serta emosional. Pendidikan jasmani adalah suatu bidang kajian yang berkaitan dengan gerak manusia, perkembangan fisik dan psikis. Menurut Fungsi pendidikan jasmani adalah aspek organik, neuromuskuler perceptual, kognitif, sosial, emosional".

Sebagaimana dikemukakan oleh Samsudin (Bayu Nugraha, 2015) menjelaskan bahwa "Pendidikan jasmani adalah suatu proses pembelajaran melalui aktivitas jasmani yang didesain untuk meningkatkan kebugaran jasmani, mengembangkan keterampilan motorik, pengetahuan dan perilaku hidup sehat, aktif, sikap sportif dan kecerdasan emosi. Lingkungan belajar diatur secara seksama untuk meningkatkan pertumbuhan dan perkembangan seluruh ranah jasmani, kognitif dan afektif setiap siswa".

"Melalui pendidikan jasmani yang diarahkan dengan baik, anak-anak akan mengembangkan keterampilan yang berguna bagi pengisian waktu senggang, terlibat dalam aktivitas yang kondusif untuk mengembangkan hidup sehat, berkembang secara sosial, dan menyumbang pada kesehatan fisik dan mentalnya" (Bayu Nugraha,2015).

\section{METODE}

Dalam penelitian ini pendekatan yang dilakukan adalah melalui pendekatan kuantitatif. Artinya data yang dikumpulkan berupa angka-angka, dan data tersebut berasal dari angket, catatan lapangan, dan dokumen pribadi. Adapun metode yang digunakan dalam penelitian in adalah metode korelasional.

Populasi yang digunakan dalam penelitian ini adalah seluruh siswa kelas XI SMA Negeri 1 Jatibarang yang berjumlah 117 orang. Teknik pengambilan sampel menggunakan teknik probability sampling dengan cara simple random sampling. Sampel yang digunakan sejumlah $50 \%$ dari populasi agar mewakili keseluruhan populasi. 50\% sampel dari jumlah populasi yaitu, 59 siswa dari anggota populasi.

Penelitian ini merupakan penelitian korelasional, karena di dalam penelitian ini bertujuan umtuk menemukan ada tidaknya hubungan antara modifikasi pemanasan dengan motivasi belajar siswa pada siswa kelas XI SMAN 1 Jatibarang. Sebagaimana dikemukakan Sukardi (2013) bahwa "Penelitian korelasi adalah suatu penelitian yang melibatkan tindakan pengumpulan data guna menentukan, apakah ada hubungan dan tingkat hubungan antara dua variabel atau lebih".

Instrumen yang digunakan dalam penelitian ini berupa angket Google Formulir yang disebar melalui Google Classroom. Karena datanya kuantitatif, maka teknik analisis data menggunakan metode statistik yang sudah tersedia. Peneliti akan melakukan uji hipotesis menggunakan korelasi product moment dari Karl Pearson, uji determinan serta uji t.

Untuk penilaian pengukuran modifikasi pemanasan dan motivasi belajar siswa, peneliti menggunakan skala Likert. Skala Likert terdiri atas sejumlah pernyataan-pernyataan tentang suatu objek, dan pernyataan ini cenderung mengekspresikan sikap yang menyenangkan dan sebagian lagi pernyataan tidak menyenangkan. Pemberian skor pada setiap kategori pernyataan yang direspon oleh responden disesuaikan dengan alternatif pilihan jawaban yaitu seperti dijelaskan pada tabel dibawah ini : 
Tabel 1. Skor Penilaian Skala Likert

\begin{tabular}{ccc}
\hline \multirow{2}{*}{ Alternatif Jawaban } & \multicolumn{2}{c}{$\begin{array}{c}\text { Skor Alternatif } \\
\text { Jawaban }\end{array}$} \\
\cline { 2 - 3 } & Positif & Negatif \\
\hline Sangat Setuju (SS) & 4 & 1 \\
\hline Setuju (S) & 3 & 2 \\
\hline Tidak Setuju (TS) & 2 & 3 \\
\hline $\begin{array}{c}\text { Sangat Tidak Setuju } \\
\text { (STS) }\end{array}$ & 1 & 4 \\
\hline
\end{tabular}

\section{HASIL DAN PEMBAHASAN}

Untuk mengetahui hubungan modifikasi pemanasan dengan motivasi belajar siswa dalam pembelajaran pendidikan jasmani pada siswa kelas XI SMA Negeri 1 Jatibarang, pengambilan data menggunakan angket dalam bentuk Google Form. Kedua angket tersebut tediri dari angket modifikasi pemanasan dengan soal total 30 butir pernyataan yang valid dan angket motivasi belajar dengan soal total 31 butir pernyataan yang valid dengan rentang skor 1 sampai 4 . Berikut deskripsi datanya dapat dilihat pada tabel berikut ini :

Tabel 2. Deskripsi Hasil Data Penelitian

\begin{tabular}{ccc}
\hline Variabel & $\begin{array}{c}\text { Modifikasi } \\
\text { Pemanasan } \\
(\mathbf{X})\end{array}$ & $\begin{array}{c}\text { Motivasi } \\
\text { Belajar } \\
(\mathbf{Y})\end{array}$ \\
\hline Nilai Tertinggi & 120 & 122 \\
\hline Nilai Terendah & 97 & 99 \\
\hline Rata-Rata & 108,96 & 110,88 \\
\hline Simpangan Baku & 5,23 & 6,02 \\
\hline
\end{tabular}

Berdasarkan tabel 2 nilai tertinggi modifikasi pemanasan 120 dan nilai terendah 97, dengan rata-rata 108,96 dan simpangan baku 5,23. Nilai tertinggi motivasi belajar 122 dan nilai terendah 99, dengan rata-rata 110,88 dan simpangan baku 6,02.

Tabel 3. Distribusi Frekuensi Variabel Modifikasi Pemanasan

\begin{tabular}{cccc}
\hline Interval Frekuensi & Nilai Frekuensi & Tengah & Relatif \\
\hline $97-100$ & 2 & 98,5 & $3,38 \%$ \\
\hline $101-104$ & 12 & 102,5 & $20,33 \%$ \\
\hline $105-108$ & 11 & 106,5 & $18,64 \%$ \\
\hline $109-112$ & 17 & 110,5 & $28,81 \%$ \\
\hline
\end{tabular}




\begin{tabular}{cccc}
\hline $113-116$ & 13 & 114,5 & $22,03 \%$ \\
\hline $117-120$ & 4 & 118,5 & $6,77 \%$ \\
\hline Jumlah & 59 & & $100 \%$ \\
\hline
\end{tabular}

Berdasarkan tabel 3 terdapat 6 kelas interval dengan panjang masing-masing interval 4, frekuensi tertinggi 17 berada di kelas interval 109-112.

Tabel 4. Distribusi Frekuensi Variabel Motivasi Belajar Siswa

\begin{tabular}{cccc}
\hline $\begin{array}{c}\text { Interval } \\
\text { Frekuensi }\end{array}$ & $\begin{array}{c}\text { Nilai } \\
\text { Frekuensi }\end{array}$ & Tengah & Relatif \\
\hline $99-102$ & 6 & 100,5 & $10,16 \%$ \\
\hline $103-106$ & 10 & 104,5 & $16,94 \%$ \\
\hline $107-110$ & 9 & 108,5 & $15,25 \%$ \\
\hline $111-114$ & 15 & 112,5 & $25,42 \%$ \\
\hline $115-118$ & 13 & 116,5 & $22,03 \%$ \\
\hline $119-122$ & 6 & 120,5 & $10,16 \%$ \\
\hline Jumlah & 59 & & $100 \%$ \\
\hline
\end{tabular}

Berdasarkan tabel 4 terdapat 6 kelas interval dengan panjang masing-masing interval 4 , frekuensi tertinggi 15 berada di kelas interval 111-114.

Uji Normalitas

Uji normalitas digunakan agar mengetahui sampel dalam penelitian ini berasal dari populasi yang berdistribusi normal atau tidak serta untuk menguji apakah yang diobservasi tidak menyimpang secara signifikan dari frekuensi yang diharapkan. Hasil pengujian normalitas menggunakan uji chi kuadrat pada tingkat kepercayaan $5 \%$. Kriteria yang digunakan untuk mengetahui normal tidaknya suatu sebaran data adalah jika nilai chi square $>$ tabel chi square sebaran dinyatakan tidak normal. Sedangkan apabila nilai chi square < tabel chi square sebaran dikatakan normal. Hasil uji normalitas dapat dilihat di bawah ini :

Tabel 5. Uji Normalitas

\begin{tabular}{ccccc}
\hline Variabel & $\begin{array}{c}\text { Nilai Chi } \\
\text { Square }\end{array}$ & $\begin{array}{c}\text { Tabel Chi } \\
\text { Square }\end{array}$ & $\begin{array}{c}\text { Sig } \\
\mathbf{5 \%}\end{array}$ & Ket \\
\hline $\begin{array}{c}\text { Modifikasi } \\
\text { Pemanasan }\end{array}$ & 3.75 & 11.07 & 0.05 & Normal \\
\hline Motivasi Belajar & 4.84 & 11.07 & 0.05 & Normal \\
\hline
\end{tabular}

Berdasarkan hasil tabel 5 diketahui data modifikasi pemanasan diperoleh nilai chi square $(3,75)$ < tabel chi square $(11,07)$ maka distribusi dinyatakan normal. Sedangkan data motivasi belajar siswa diperoleh nilai chi square $(4,84)<$ tabel chi square $(11,07)$ maka distribusi dinyatakan normal. Dengan demikian kedua data berdistribusi normal.

Uji Homogenitas

Uji homogenitas dari data hasil sebaran tersebut dengan menggunakan uji homogenitas fisher's. Tujuannya adalah untuk menetapkan bahwa data tersebut bersifat homogen atau tidak. Hasil pengujian tersebut sebagai berikut:

Tabel 6. Uji Homogenitas

\begin{tabular}{cccc}
\hline \multicolumn{2}{c}{ Varians } & Fhitung & Ftabel \\
\hline $\mathrm{X}$ & $\mathrm{Y}$ & & \\
\hline
\end{tabular}




\begin{tabular}{llll}
\hline 28,55 & 36,96 & 1,29 & 1.54 \\
\hline
\end{tabular}

Berdasarkan hasil pengujian pada tabel 6 diketahui nilai Fhitung $(1,29)<$ Ftabel $(1,54)$ maka dapat disimpulkan bahwa kedua sampel berasal dari populasi homogen.

Uji Korelasi

Untuk mengetahui korelasi antara modifikasi pemanasan dengan motivasi belajar siswa dalam pembelajaran pendidikan jasmani, maka digunakan rumus Pearson Product Moment Correlattion dengan bantuan computer melalui program Microsoft Excel 2010, adapun hasil tersebut adalah sebagai berikut:

Tabel 7. Pearson Correlattion

\begin{tabular}{c|c}
\hline \multicolumn{2}{c}{ Regression Statistics } \\
\hline Multiple $R$ & 0,739 \\
\hline Observations & 59 \\
\hline
\end{tabular}

Berdasarkan tabel 7 hasil korelasi Pearson Product Moment, menunjukan bahwa hasil korelasinya adalah sebesar 0,739 . Oleh karena itu untuk mengetahui bobot/beratnya hubungan antara modifikasi pemanasan dengan motivasi belajar siswa, maka harus melihat pedoman koefisien korelasi di bawah ini:

Tabel 8. Interpretasi Koefisien Korelasi

\begin{tabular}{cc}
\hline Interval & Tingkat Hubungan \\
\hline $0,00-0,199$ & Sangat Rendah \\
\hline $0,20-0,399$ & Rendah \\
\hline $0,40-0,599$ & Sedang \\
\hline $0,60-0,799$ & Kuat \\
\hline $0,80-1,000$ & Sangat Kuat \\
\hline
\end{tabular}

Hasil korelasi di atas sebesar 0,739 termasuk ke dalam tingkat hubungan yang kuat. Artinya bahwa modifikasi pemanasan memiliki hubungan yang kuat dengan motivasi belajar siswa dalam pembelajaran pendidikan jasmani pada siswa kelas XI SMAN 1 Jatibarang.

Uji Determinan

Uji Determinan berdasarkan tabel 7 diketahui bahwa $r$ adalah 0,739 berarti terdapat hubungan yang kuat antara modifikasi pemanasan dengan motivasi belajar siswa. Untuk $R$ square ( $R$ kuadrat) berarti $0,739^{2}=0,546$ berarti diperoleh koefisien determinan : $0,546 \times 100 \%$ $=54,61 \%$. Dari hasil perhitungan rumus tersebut, maka dapat disimpulkan bahwa hubungan variabel $X$ dengan variabel $Y$, atau hubungan modifikasi pemanasan dengan motivasi belajar siswa sebesar $54,61 \%$ sedangkan sisanya $45,39 \%$ berhubungan dengan faktor-faktor lain.

Uji T

Untuk menguji dan menjawab hipotesis tersebut, maka dilakukan perhitungan menggunakan uji $\mathrm{t}$ dan hasil yang diperoleh adalah sebagai berikut :

Tabel 9. Data Hasil Uji T

\begin{tabular}{ccc}
\hline Thitung & Ttabel & Kesimpulan \\
\hline 8,139 & 2,002 & Signifikan \\
\hline
\end{tabular}

Dari hasil pengujian data pada tabel 9 diperoleh bahwa thitung 8,138 lebih besar dari ttabel 2,002. Jadi $\mathrm{H} 0$ ditolak dan $\mathrm{H} 1$ diterima, maka dapat disampaikan bahwa terdapat hubungan yang signifikan antara modifikasi pemanasan dengan motivasi belajar siswa dalam pembelajaran 
pendidikan jasmani pada siswa kelas XI SMAN 1Jatibarang. Waktu Penelitian Waktu penelitian dilaksanakan pada tanggal 11 agustus 2020 sampai dengan 14 agustrus 2020.

Lokasi Penelitian

Lokasi penelitian ini dilakukan di SMA Negeri 1 Jatibarang, dikarenakan sedang dalam masa pandemi COVID-19 sekolahpun melakukan aktivitas kegiatan belajar mengajar dengan metode Daring dan tidak disarankan tatap muka maka pengambilan data penelitianpun melalui Google Classroom dengan menyebar link Google Form untuk diisi oleh sampel yang telah ditentukan.

\section{KESIMPULAN}

Berdasarkan hasil penelitian, maka diketahui ada hubungan signifikan antara Modifikasi Pemanasan dengan Motivasi Belajar Siswa dalam Pembelajaran Pendidikan Jasmani.Hasil penelitian ini dapat dilihat dari diterimanya hipotesis yang peneliti ajukan. Temuan dalam penelitian tersebut yaitu dengan pemanasan yang dimodifikasi dalam bentuk permainan membuat suasana belajar lebih aktif dan menjadikan motivasi belajar siswa dalam pembelajaran pendidikan jasmani meningkat. Hal ini dapat dilihat dari hasil uji determinan yang menghasilkan $54,61 \%$ modifikasi pemanasan menjadi faktor penting dalam hubungannya dengan motivasi belajar dan sisanya $45,39 \%$ berhubungan dengan faktor lain. Serta hasil penghitungan korelasi menunjukan angka 0,739 maka dari itu modifikasi pemanasan dengan motivasi belajar siswa berhubungan kuat.

\section{DAFTAR PUSTAKA}

A.M, S a r d i m a n . (2010). Interaksi dan Motivasi Belajar Mengajar. Jakarta: Rajawali Pers.

Adang Suherman dan Yoyo Bahagia. (2010). Prinsip-prinsip Pengembangan dan Modifikasi Cabang Olahraga. Jakarta: Depdiknas.

Bahagia, Yoyo. (2010). Media dan Pembelajaran Penjas. Bandung: FPOK UPI. Hamalik, Oemar. (2011). Proses Belajar Mengajar. Jakarta: Bumi Aksara.

Hamzah B. Uno. (2011). Teori Motivasi dan Pengukurannya: Analisis di Bidang Pendidikan. Jakarta: Bumi Aksara.

Hartono, Soetanto, dkk. (2013). Pendidikan Jasmani (sebuah pengantar). Surabaya: Universitas Negeri Surabaya University Press.

Husdarta. (2010). Psikologi Olahraga. Bandung: Alfabeta.

Kristiandaru. (2010). Manajemen Pendidikan Jasmani dan Olahraga. Surabaya: Universitas Negeri Surabaya University Press.

Mutohir. (2011). Berkarakter dengan Berolahraga, Berolahraga dengan Berkarakter. Surabaya: PT. Java Pustaka.Group.

Sukardi. (2013). Metodologi Penelitian Pendidikan : Kompetensi dan Praktiknya. Jakarta: PT. Bumi Aksara.

Anggoro, Turas Rio. (2016). "Pengaruh Latihan Pembebanan terhadap Power Tungkai Atlet Taekwondo Junior DIY".Jurnal IImiah Pendidikan Jasmani. 3(1), 84.

Faizal, Muhammad. dan Hartoto, Setyo. (2015). "Pengaruh Modifikasi Pembelajaran Underpass Permainan Bolavoli terhadap Minat Siswa Kelas V SD dalam Mengikuti Mata Pelajaran Penjasorkes". Ejournal.unesa.ac.id jurnal pendidikan jasmani. 3, 350. 
Fauziah, Eva. (2013). Hubungan Faktor-Faktor yang Mempengaruhi Motivasi dalam Mengikuti Pelajaran Pendidikan Jasmani. Jurnal Unila. 3, 19.

Gusril. (2014). Efektifitas Rancangan Modifikasi Olahraga ke dalam Penjas. Jurnal Nasional Penjas dan IImu Keolahragaan. 3(1).

Nugraha, Bayu. (2015). "Pendidikan Jasmani Olahraga Usia Dini”. Jurnal Pendidikan Anak. 4(1), 559-560. 